\title{
Standard- versus intermediate-dose enoxaparin for anti-factor Xa guided thromboprophylaxis in critically ill patients with COVID-19
}

David Oliver Hamilton ${ }^{1,2}$, Alexander Main-lan'1, Jessie Tebbutt ${ }^{1}$, Maya Thrasher ${ }^{1}$, Alicia Waite ${ }^{1,2}$ and Ingeborg Welters ${ }^{1,2^{*}}$ (D)

\begin{abstract}
The prevalence of venous thromboembolism (VTE) is high in critically ill patients with COVID-19. Dosing of Low Molecular Weight Heparin (LMWH) for thromboprophylaxis in patients with severe COVID-19 is subject to ongoing debate.

In this brief report, we describe our study where we retrospectively examined the efficacy of standard- versus intermediate-dosing of enoxaparin in attaining and maintaining accepted prophylactic levels of anti-Factor Xa (antiFXa) in critically ill patients with COVID-19.

We collected data for all patients with confirmed COVID-19 who were treated with enoxaparin for thromboprophylaxis in a single Intensive Care Unit (ICU) in the United Kingdom between 31st March and 16th November 2020. Standard-dose of enoxaparin was $40 \mathrm{mg}$ subcutaneously once daily for patients with normal renal function and body weight between 50 and $100 \mathrm{~kg}$; the intermediate-dose was $40 \mathrm{mg}$ subcutaneously twice daily. Anti-FXa peak concentrations between $0.2-0.4 \mathrm{IU} / \mathrm{ml}$ were considered appropriate for thromboprophylaxis. Age, sex, weight, Body Mass Index, APACHE II score, ICU length of stay, initial P/F ratio and creatinine were not statistically significantly different between standard- and intermediate-dose thromboprophylaxis cohorts. In the standard-dose group, the median initial anti-FXa level was 0.13 (interquartile range $0.06-0.18$ ) compared to 0.26 $(0.21-0.33)$ in the intermediate-dose cohort $(p<0.001)$. On repeated measurement, in the standard dose cohort, 44 of $95(46 \%)$ anti-FXa levels were $<0.2 \mathrm{IU} / \mathrm{ml}$ compared with 24 of $132(18 \%)$ levels in the intermediate-dose cohort even after dose-adjustment. There was one radiologically confirmed pulmonary embolism (PE) on computed tomography pulmonary angiogram during hospital admission in each cohort.

Our study supports starting intermediate-dose thromboprophylaxis for critically ill patients with COVID-19 to achieve anti-FXa levels in the accepted thromboprophylactic range although further study is required to investigate whether anti-FXa guided thromboprophylaxis is safe and effective in reducing the incidence of VTEs in critically ill patients with COVID-19.
\end{abstract}

\footnotetext{
* Correspondence: I.Welters@liverpool.ac.uk

'Critical Care Department, Royal Liverpool University Hospital, Prescot St, Liverpool, UK

${ }^{2}$ Institute of Life Course and Medical Sciences, University of Liverpool,

Liverpool, UK
}

\section{$\triangle B M C$}

(c) The Author(s). 2021 Open Access This article is licensed under a Creative Commons Attribution 4.0 International License, which permits use, sharing, adaptation, distribution and reproduction in any medium or format, as long as you give appropriate credit to the original author(s) and the source, provide a link to the Creative Commons licence, and indicate if changes were made. The images or other third party material in this article are included in the article's Creative Commons licence, unless indicated otherwise in a credit line to the material. If material is not included in the article's Creative Commons licence and your intended use is not permitted by statutory regulation or exceeds the permitted use, you will need to obtain permission directly from the copyright holder. To view a copy of this licence, visit http://creativecommons.org/licenses/by/4.0/ The Creative Commons Public Domain Dedication waiver (http://creativecommons.org/publicdomain/zero/1.0/) applies to the data made available in this article, unless otherwise stated in a credit line to the data. 


\section{Brief report}

The prevalence of venous thromboembolism (VTE) is high in critically ill patients with COVID-19 [1]. Dosing of Low Molecular Weight Heparin (LMWH) for thromboprophylaxis in patients with severe COVID-19 is subject to ongoing debate. Several guidelines suggest the use of an 'intermediate' dose of LMWH instead of standard dosing [1-3]. Anti-Factor Xa (anti-FXa) monitoring has been used to titrate LMWH doses for prophylactic or therapeutic anticoagulation in critically ill patients [4]. Results of a recent randomised clinical trial do not support routine use of intermediate-dose prophylactic anticoagulation in patients with COVID-19, however anti-FXa levels were not measured in this study [5].

In this study, we retrospectively examined the efficacy of standard- versus intermediate-dosing of enoxaparin in attaining and maintaining accepted prophylactic levels of anti-FXa in critically ill patients with COVID-19.

We collected data for all patients with confirmed COVID-19 who were treated with enoxaparin for thromboprophylaxis in the Royal Liverpool University Hospital Intensive Care Unit (ICU) between 31st March and 16th November 2020 who had at least one anti-FXa level measured. Patients on therapeutic anticoagulation, patients transferred in from other ICUs or those deemed to have an incidental diagnosis of COVID-19 were excluded.

Standard-dose of enoxaparin was $40 \mathrm{mg}$ subcutaneously once daily for patients with normal renal function and body weight between 50 and $100 \mathrm{~kg}$; the intermediate-dose was $40 \mathrm{mg}$ subcutaneously twice daily.
From 21st April 2020, our institution changed to intermediate-dose LMWH, with further dose adjustments guided by anti-FXa levels, for prophylaxis as the standard of care after early evidence for COVID-19associated coagulopathy emerged [1, 6-8]. This change allowed the comparison of two cohorts: patients receiving standard-dosing and patients receiving intermediatedosing. There were no further changes to the thromboprophylaxis protocol through the study period.

Anti-FXa levels were measured after at least three consecutive doses of enoxaparin (Inhixa, Techdow Pharmaceuticals, Shenzhen, China). Peak anti-FXa levels were obtained four hours after dose administration and quantified using citrated plasma (Sodium Citrate S-Monovette, Sarstedt, North Carolina, USA) in a chromogenic assay (HemosIL Liquid Anti-Xa, Instrumentation Laboratory, Bedford, USA). The test is accurate to a detection limit $<0.04 \mathrm{IU} / \mathrm{ml}$ and has a coefficient of variation value of $<6 \%$ [9]. It should be noted that dextran is included in the reaction mixture used in both cohorts and no blood tubes used contained the Citrate Theophylline Adenosine Dipyridamole (CTAD) mixture.

Anti-FXa concentrations between $0.2-0.4 \mathrm{IU} / \mathrm{ml}$ were considered appropriate for thromboprophylaxis $[1,4,10$, 11]. Dose adjustments were made at clinicians' discretion if levels were not in range. Anti-FXa monitoring was repeated after dose adjustments or weekly if levels were within range.

Data were collected retrospectively from routine clinical data until death, ICU discharge or day 14 of ICU

Table 1 Characteristics and results for standard-dose cohort (left) and intermediate-dose cohort (right)

\begin{tabular}{|c|c|c|c|c|c|c|c|}
\hline & \multicolumn{3}{|c|}{ Standard-dose } & \multicolumn{3}{|c|}{ Intermediate-dose } & \multirow[t]{2}{*}{$p$-value } \\
\hline & $\mathrm{n}$ & Median & IQR & $\mathrm{n}$ & Median & IQR & \\
\hline Age (years) & 23 & 58 & {$[46.5-63.5]$} & 35 & 53 & {$[45.5-67]$} & $p=0.874$ \\
\hline Weight (kg) & 23 & 90 & {$[79-96.5]$} & 35 & 86 & {$[76.5-98]$} & $p=0.427$ \\
\hline Body Mass Index & 23 & 30.3 & {$[25.8-32.0]$} & 35 & 29 & {$[24.8-31.3]$} & $p=0.276$ \\
\hline APACHE \| Score & 20 & 12.5 & {$[11.8-15.3]$} & 32 & 12.5 & {$[10-16.3]$} & $p=0.699$ \\
\hline Critical Care admission (days) & 23 & 19 & {$[12-22]$} & 34 & 15 & {$[9.3-21]$} & $p=0.353$ \\
\hline P/F Ratio (kPa) & 23 & 19.4 & {$[15.3-26.9]$} & 35 & 18.5 & {$[15.4-25.3]$} & $p=0.674$ \\
\hline PEEP $(\mathrm{cmH} 2 \mathrm{O})$ & 22 & 11 & {$[8.5-12.8]$} & 34 & 10 & {$[7.5-10]$} & $p=0.033$ \\
\hline Noradrenaline (mcg/kg/min) & 23 & 0 & {$[0-0.01]$} & 35 & 0 & {$[0-0]$} & $p=0.053$ \\
\hline Creatinine (micromol/L) & 23 & 74 & {$[57-99]$} & 35 & 64 & {$[53-81]$} & $p=0.097$ \\
\hline Estimated fluid balance (ml) & 23 & 2800 & {$[1650-6250]$} & 33 & 700 & {$[0-1900]$} & $p<0.001$ \\
\hline First Anti-Factor Xa level (IU/ml) & 23 & 0.13 & {$[0.06-0.18]$} & 35 & 0.26 & {$[0.21-0.33]$} & $p<0.001$ \\
\hline Starting daily dose enoxaparin (mg) & 23 & 40 & {$[40-40]$} & 35 & 80 & {$[80-80]$} & $p<0.001$ \\
\hline Dose by weight (mg/kg) & 23 & 0.44 & {$[0.42-0.51]$} & 35 & 0.93 & {$[0.82-1.04]$} & $p<0.001$ \\
\hline Adjustment period (days) & 16 & 2 & {$[0-3]$} & 34 & 0 & {$[0-0.8]$} & $p=0.003$ \\
\hline
\end{tabular}

$I Q R$ Inter-quartile range, $P E E P$ positive end expiratory pressure.

Bold text highlights statistical significance. 


\section{a. Standard-dose}

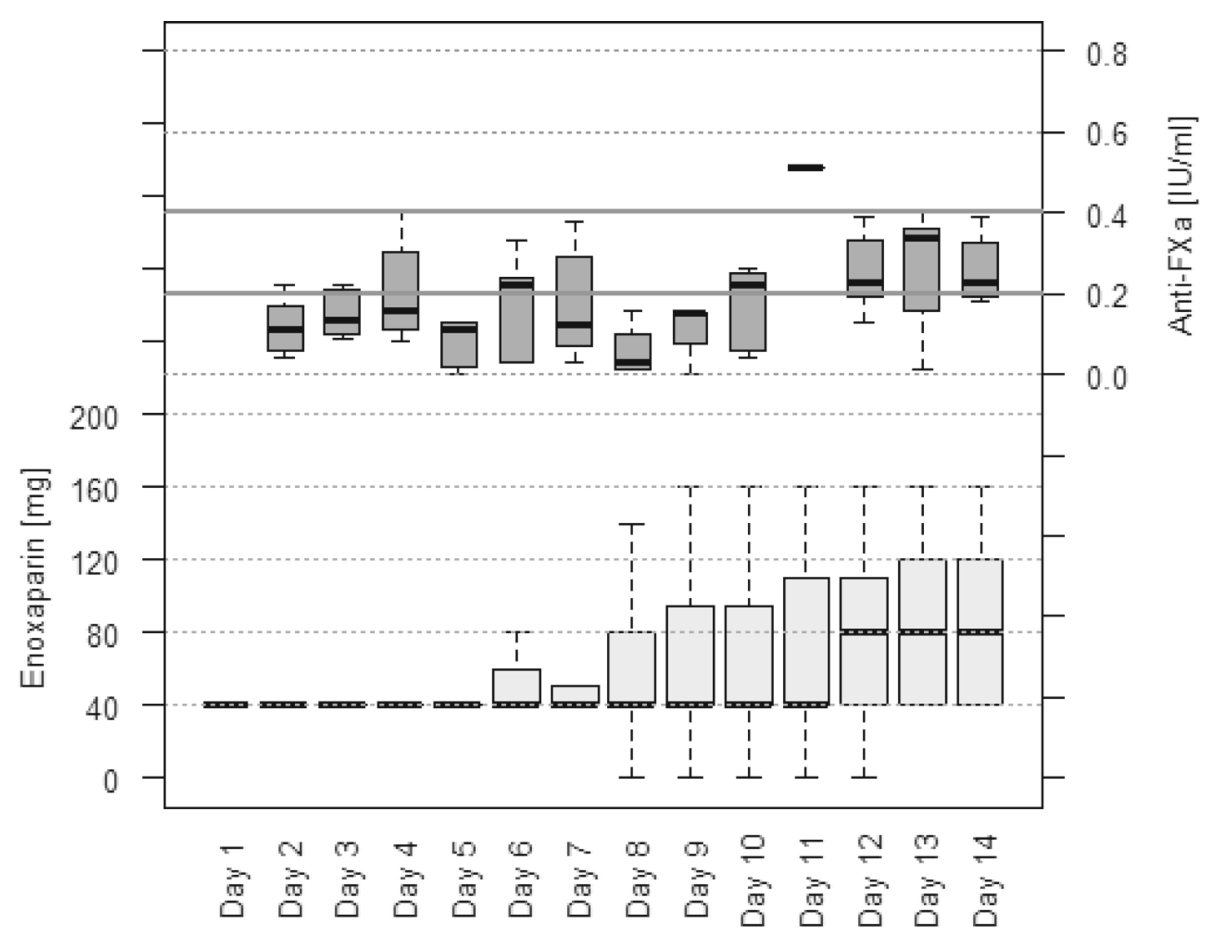

b. Intermediate-dose

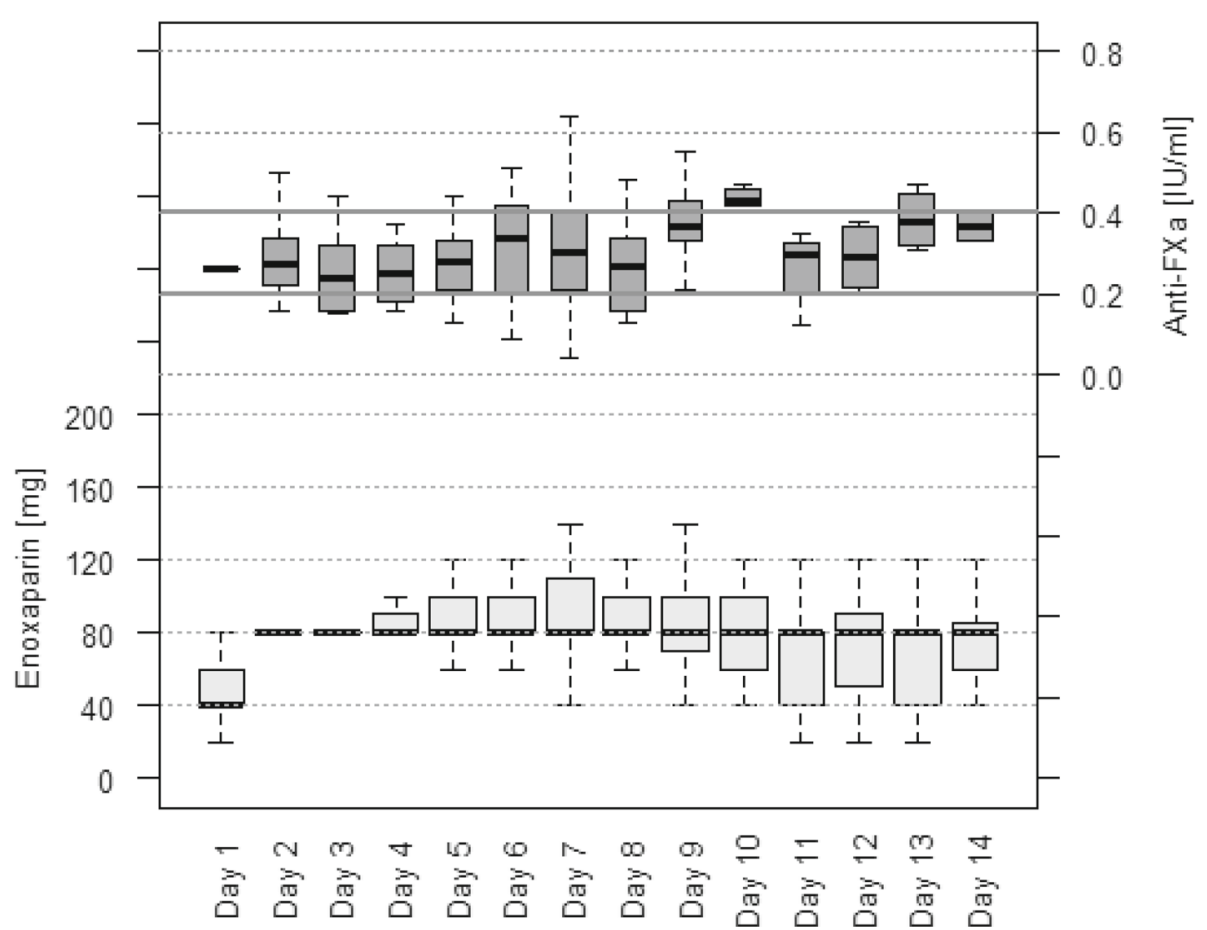

Fig. 1 Anti-Factor Xa levels and total daily enoxaparin dose administered across for the first 14 days of Intensive Care Unit (ICU) admission for standard-dose (a) and intermediate-dose cohorts (b). Doses were adjusted throughout admission at clinicians' discretion. Day 1 reflects admission day to ICU, therefore depending on the time of admission, patients in the intermediate-dose cohort received either two or only one dose of enoxaparin 
admission. Approval for the study was given by the hospital's Clinical Effectiveness department. Data were analysed using R 3.6.3 for MS Windows. Comparison between standard- and intermediate-dose thromboprophylaxis was made using Fisher's exact test for categorical data and Mann-Whitney $\mathrm{U}$ test for numeric data. $P$ values $<0.05$ were considered significant.

Age, sex, weight, Body Mass Index, APACHE II score, ICU length of stay, initial $\mathrm{P} / \mathrm{F}$ ratio and creatinine were not statistically significantly different between standardand intermediate-dose thromboprophylaxis cohorts (Table 1). Inpatient mortality was $43.1 \%, 11$ out of 23 $(47.8 \%)$ patients in the standard-dose cohort and 14 out of $35(40.0 \%)$ in the intermediate-dose cohort.

In the standard-dose group, the median initial antiFXa level was 0.13 (interquartile range 0.06-0.18) compared to $0.26(0.21-0.33)$ in the intermediate-dose cohort $(p<0.001)$.

Ninety-five anti-FXa levels were measured in the standard-dose cohort. Forty-four (46\%) of these measurements were below $0.2 \mathrm{IU} / \mathrm{ml}$ compared with 24 of $132(18 \%)$ levels in the intermediate-dose cohort. Ten of the $58(17 \%)$ patients included had only one anti-Xa level measured, hence the majority of patients had repeated measurements to allow assessment on maintaining appropriate anti-FXa levels. Patients with only one measurement had either died, been changed to therapeutic anticoagulation or were discharged early after admission.

Figure 1a\&b show the anti-FXa levels for standard and intermediate dosing for the first 14 days of ICU admission. In Fig. 1a\&b, Day 1 represents admission to ICU, and shows a high variation in the dose of enoxaparin administered as it was typically prescribed at 06:00 and 18: 00 and therefore the time of admission in the day would affect the dose received by the patient.

In each cohort, one patient had pulmonary embolism (PE) confirmed on computed tomography pulmonary angiogram during hospital admission. In total, 18 patients required escalation to therapeutic anticoagulation (standard-dose cohort: 6 patients, intermediate-dose cohort: 12 patients), for the following reasons: empiric PE treatment after deterioration (10 patients, four of whom later had imaging, all of which was negative); atrial fibrillation (three patients); confirmed PE (two patients); extracorporeal membrane oxygenation (two patients) and renal replacement therapy (one patient). There were no major bleeding events as defined by the International Society on Thrombosis and Haemostasis criteria [12].

These data suggest that intermediate-dose is more likely to result in accepted anti-FXa levels sufficient for thromboprophylaxis compared to standard-dosing. This implies that critically ill patients with COVID-19 may be at risk from VTE or immunothromboses if treated with standard-dose enoxaparin. This may be due to the high level of circulating acute phase reactants, such as fibrinogen, neutrophil extracellular traps and histones [1]. It may also be a feature of critical illness itself. Anti-FXa levels are markedly lower in critically ill patients with COVID-19 on standard-dosing compared to ward-based patients [11]. Pre-pandemic literature also suggests that conventional standard-dose LMWH was associated with low anti-FXa levels in critically ill patients [13, 14].

There are several limitations to this study: firstly, the results of this small single-centre study may not be applicable in different settings or to the use of other LMWH or anti-FXa testing procedures. Larger prospective studies are required to confirm that intermediatedosing of LMWH is more reliable in attaining satisfactory anti-FXa levels for thromboprophylaxis. Secondly, adjusting thromboprophylaxis to target anti-FXa levels has not been shown to improve clinical outcomes in critical illness [15]; and there is no universally accepted target range. Further research is required to assess the efficacy, safety and reproducibility of anti-FXa guided thromboprophylaxis.

In conclusion, our study supports the use of intermediate-dose thromboprophylaxis for critically ill patients with COVID-19 to achieve anti-FXa levels considered appropriate for thromboprophylaxis. However, monitoring of anti-FXa levels has not been shown to improve clinical outcomes in critical illness. The efficacy of intermediate-dose thromboprophylaxis for prevention of venous thromboembolism (VTE) remains uncertain, and larger clinical trials are needed to investigate whether anti-FXa guided thromboprophylaxis is safe and effective in reducing the incidence of VTEs in critically ill patients with COVID-19.

\section{Acknowledgements \\ We thank Mr. Martin Mogk for support in production of the figures.}

\section{Authors' contributions}

$\mathrm{DOH}, \mathrm{AW}$ and IW planned the study, analysed the data and wrote the manuscript. DOH, AMI, JT, MT collected data. All authors approved the finalised draft.

\section{Funding}

The work was funded by the Department of Critical Care, Liverpool University Hospitals NHS Foundation Trust. Article Processing Charge by the University of Liverpool.

Availability of data and materials

Availability of data depends on approval by Liverpool University Hospitals NHS Foundation Trust.

\section{Declarations}

Ethics approval and consent to participate

In line with national guidance.

(http://www.hra-decisiontools.org.uk/research/docs/DefiningResearchTable_ Oct2017-1.pdf) this project was classified as clinical audit and approved by the Clinical Effectiveness Team (CAMS ref.: 8549). Ethical approval is therefore not required. 


\section{Consent for publication}

All authors have read the final manuscript and consented to publication.

\section{Competing interests}

None of the authors have declared a competing interest.

Received: 7 July 2021 Accepted: 24 October 2021

Published online: 15 November 2021

\section{References}

1. Waite AAC, Hamilton DO, Pizzi R, Ageno W, Welters ID. Hypercoagulopathy in severe COVID-19: implications for acute care. Thromb Haemost. 2020; 120(12):1654-67.

2. Barnes GD, Burnett A, Allen A, et al. Thromboembolism and anticoagulant therapy during the COVID-19 pandemic: interim clinical guidance from the anticoagulation forum. J Thromb Thrombolysis. 2020;50(1):72-81.

3. FICM. Rapid Update to FICM/ICS Clinical guide for the management of critical care for adults with COVID-19 during the Coronavirus pandemic 2021. https://icmanaesthesiacovid-19.org/covid-cc-guideline-update (accessed 2nd October 2021 2021).

4. Robinson S, Zincuk A, Strøm T, Larsen TB, Rasmussen B, Toft P. Enoxaparin, effective dosage for intensive care patients: double-blinded, randomised clinical trial. Crit Care. 2010;14(2):R41.

5. Investigators I. Effect of intermediate-dose vs standard-dose prophylactic anticoagulation on thrombotic events, extracorporeal membrane oxygenation treatment, or mortality among patients with COVID-19 admitted to the intensive care unit: the INSPIRATION randomized clinical trial. JAMA. 2021;325(16):1620-30.

6. Klok FA, Kruip MJHA, van der Meer NJM, et al. Incidence of thrombotic complications in critically ill ICU patients with COVID-19. Thromb Res. 2020; 191:145-7.

7. Middeldorp S, Coppens M, van Haaps TF, et al. Incidence of venous thromboembolism in hospitalized patients with COVID-19. J Thromb Haemost. 2020;18(8):1995-2002.

8. Helms J, Tacquard C, Severac F, et al. High risk of thrombosis in patients with severe SARS-CoV-2 infection: a multicenter prospective cohort study. Intensive Care Med. 2020:46(6):1089-98.

9. FDA. 510(k) Substantial Equivalence Determination Decision Summary https://www.accessdata.fda.gov/cdrh_docs/reviews/K090209.pdf (accessed 2nd October 2021).

10. Wei MY, Ward SM. The Anti-Factor Xa Range For Low Molecular Weight Heparin Thromboprophylaxis. Hematol Rep. 2015;7(4):5844.

11. Dutt T, Simcox D, Downey C, et al. Thromboprophylaxis in COVID-19: antiFXa-the missing factor? Am J Respir Crit Care Med. 2020;202(3):455-7.

12. Kaatz S, Ahmad D, Spyropoulos AC, Schulman S. Definition of clinically relevant non-major bleeding in studies of anticoagulants in atrial fibrillation and venous thromboembolic disease in non-surgical patients: communication from the SSC of the ISTH. J Thromb Haemost. 2015;13(11): 2119-26.

13. Mayr AJ, Dünser M, Jochberger $S$, et al. Antifactor Xa activity in intensive care patients receiving thromboembolic prophylaxis with standard doses of enoxaparin. Thromb Res. 2002;105(3):201-4.

14. Priglinger U, Delle Karth G, Geppert A, et al. Prophylactic anticoagulation with enoxaparin: Is the subcutaneous route appropriate in the critically ill? Crit Care Med. 2003;31(5):1405-9.

15. Vahtera A, Valkonen $\mathrm{M}$, Huhtala $\mathrm{H}$, Pettilä V, Kuitunen A. Plasma anti-FXa concentration after continuous intravenous infusion and subcutaneous dosing of enoxaparin for thromboprophylaxis in critically ill patients. A randomized clinical trial. Thromb Res. 2017;158:71-5.

\section{Publisher's Note}

Springer Nature remains neutral with regard to jurisdictional claims in published maps and institutional affiliations.

Ready to submit your research? Choose BMC and benefit from:

- fast, convenient online submission

- thorough peer review by experienced researchers in your field

- rapid publication on acceptance

- support for research data, including large and complex data types

- gold Open Access which fosters wider collaboration and increased citations

- maximum visibility for your research: over $100 \mathrm{M}$ website views per year

At $\mathrm{BMC}$, research is always in progress.

Learn more biomedcentral.com/submissions 